\title{
OECD Ülkelerinde Ar-Ge Teşvikleri ve İnovasyon İlişkisi Üzerine Ampirik Bir İnceleme ${ }^{1}$
}

\author{
Nisa SEÇÍLMİ̧̧ \\ Dr. Öğr. Üyesi, Gaziantep Üniversitesi, Havacılık ve Uzay Bilimleri Fakültesi, \\ Havacılık Yönetimi Bölümü \\ nsecilmis@gantep.edu.tr \\ Orcid ID: https://orcid.org/0000-0003-2487-2105
}

\author{
Aylin KONU \\ Dr. Öğr. Üyesi, Gaziantep Üniversitesi, İktisadi ve İdari Bilimler Fakültesi, \\ Uluslararası Ticaret ve Lojistik Bölümü \\ akoc@gantep.edu.tr \\ Orcid ID: https://orcid.org/0000-0002-6260-6812
}

\begin{abstract}
Öz
Bilgi ekonomisi çağında Ar-Ge faaliyetleri yapmak bir ihtiyaçtan ziyade zorunluluktur. İnovasyonun ve teknolojik gelişmenin ekonomik büyümenin merkezine taşınmasıyla birlikte Ar-Ge göstergeleri bir iktisadi gelişmişlik ölçütü olarak kullanılmaktadır. Firmaların ve ülke ekonomilerinin güçlü olması yeniliği ne kadar iyi ve ne kadar kısa zamanda yakaladıkları ile orantılıdır. Günümüz dünya ekonomisinde önemi her geçen gün artan yenilik faaliyetlerini teşvik etmek amaciyla devlet, özel sektöre doğrudan ve dolaylı yolla destek sağlamaktadır.

$\mathrm{Bu}$ çalışmanın amacı, söz konusu teşviklerin ulusal bazda geliştirilen inovasyon üzerindeki etkisini OECD ülkeleri için 2016 yılı verilerini kullanarak yatay-kesit analiz yöntemi ile ölçmektir. Çalışmadan elde edilen ampirik sonuçlara göre, OECD ülkelerinde Ar-Ge teşviklerinin inovasyon üzerinde istatistiksel olarak anlamlı bir etkiye sahip olmadığı bulgusuna ulaşılmıştır.
\end{abstract}

Anahtar Kelimeler: Ar-Ge Teşvikleri, İnovasyon, OECD.

\footnotetext{
${ }^{1}$ Makale Geliş/Kabul Tarihi: 27.02.2019 / 22.08.2019

Künye Bilgisi: Seçilmiş, N. ve Konu, A. (2019). OECD Ülkelerinde Ar-Ge Teşvikleri ve Inovasyon İlişkisi Üzerine Ampirik Bir İnceleme. Kahramanmaraş Sütçü İmam Üniversitesi Sosyal Bilimler Dergisi, 16 (2), 686-702. DOI: 10.33437/ksusbd.533175
} 


\title{
An Empirical Study on R \& D Incentives and Innovation Relation in OECD Countries
}

\begin{abstract}
R\&D activities in the age of knowledge economy are a necessity rather than a need. With the transfer of innovation and technological development to the center of economic growth, $R \& D$ indicators are used as a measure. The strengths of firms and economies are proportional to how well and how quickly they catch up with innovation. The government provides direct and indirect support to the private sector in order to promote innovation activities that are becoming increasingly important in today's World economy.

The purpose of this study is to measure the impact of these incentives on innovation by using the cross-sectional analysis method for 2016 data of OECD countries. According to the empirical results obtained from the study, it was found that R\&D incentives in OECD countries did not have a statistically significant effect on innovation.
\end{abstract}

Keywords: R\&D Incentives, Innovation, OECD.

\section{GíRiş}

Teknolojik bilgi birikimi, Neo-Klasik büyüme modelleri ile içselleştirilerek ekonomik büyüme üzerinde önemli etkisi olduğu ortaya konulmuştur. Bilgi birikiminin ekonomik büyüme ile bütünleștirilmesiyle birlikte $\mathrm{Ar}-\mathrm{Ge}$ ve yenilik faaliyetleri ön plana çıkmaya başlamış ve uluslararası rekabet için önemi anlaşılmışıır. Küresel rekabet ortamında firmaların, endüstrilerin, bölgelerin ya da ülkelerin başarısı, katma değeri yüksek bir üretim yapmaktan geçmekte, bu sistemin kurulabilmesi ve sürdürülebilirliği ise Ar-Ge faaliyetlerinin sürekliliği ile sağlanabilmektedir. Sürdürülebilir ekonomik büyüme için önem arz eden ArGe faaliyetleri yürütülürken, kamu ve özel sektörün ortak hareket etmesi sürecin etkinliğini artırdığından, birçok ülke spesifik politika araçları geliştirerek yenilik sürecinde firmalara destek olmaktadır (Akçomak ve Kalaycı, 2016: 2).

İnovasyona yönelik geliştirilen politika araçlarının başarısı, istikrarlı bir makroekonomik çevre; sağlam bir kamu maliyesi; iyi işleyen finansal, emek ve ürün piyasaları; etkili vergi, ticaret ve düzenleme politikaları ile sağlanabilmektedir. Büyük yeni fikirler iyi yürütülen Ar-Ge faaliyetlerine dayanırken, yeni fikirlerin etkili biçimde ticari olarak uygulanabilmesi, sadece araştırma yapmanın ötesinde, piyasanın rekabet derecesi, fikri mülkiyet sistemi ve finansal ulaşılabilirlik gibi birçok faktöre bağlıdır (Bernanke, 2011: 3). 
$\mathrm{Bu}$ çalışmada devletin özel sektöre sağladığ 1 toplam teşviklerin ülke inovasyon faaliyetleri üzerindeki etkisi incelenerek söz konusu teşviklerin başarılı olup olmadığı araştırılacaktır. Bu amaçla öncelikle kamu sektörünün ArGe faaliyetleri içerisindeki rolüne değinilecek, daha sonra inovasyon ve Ar-Ge arasındaki ilişki incelenecektir. Son olarak toplam devlet teşviklerinin inovasyon üzerindeki etkisi OECD ülkeleri için 2016 verileri kullanılarak yatay kesit analiz yöntemi ile test edilecektir.

\section{İNOVASYON SÜRECINDE DEVLETIN FONKSIYYONU}

Geçtiğimiz iki yüz yıl boyunca yeni inovasyon, teknik gelişmeler ve sermaye mallarına yapılan yatırım dünya ekonomilerini değiştirmiş ve inovasyon ve teknolojik değişim büyüme sürecinin temel dinamiği haline gelmiştir (Bernanke, 2011:2). İnovasyonun öneminin fark edilmesi ile ülkeler, Ar-Ge yoğun bir üretim sürecini tercih etmeye bu sürecine ağırlık vererek yenilik faaliyetlerinin avantajlarından faydalanma çabasına girmişlerdir. Dünya genelinde artan bu eğilim sürecini Şekil 1'e bakarak da görmek mümkündür. Şekilde, 2000 ve 2016 yıllarında OECD ülkelerindeki Ar-Ge yoğunluğu (Ar-Ge harcamalarının ülke GSMH'sına oranı) verilmiştir.

Şekil 1: OECD Ülkelerinin 2000 ve 2016 Yıllarındaki Ar-Ge Yoğunlukları (\%)

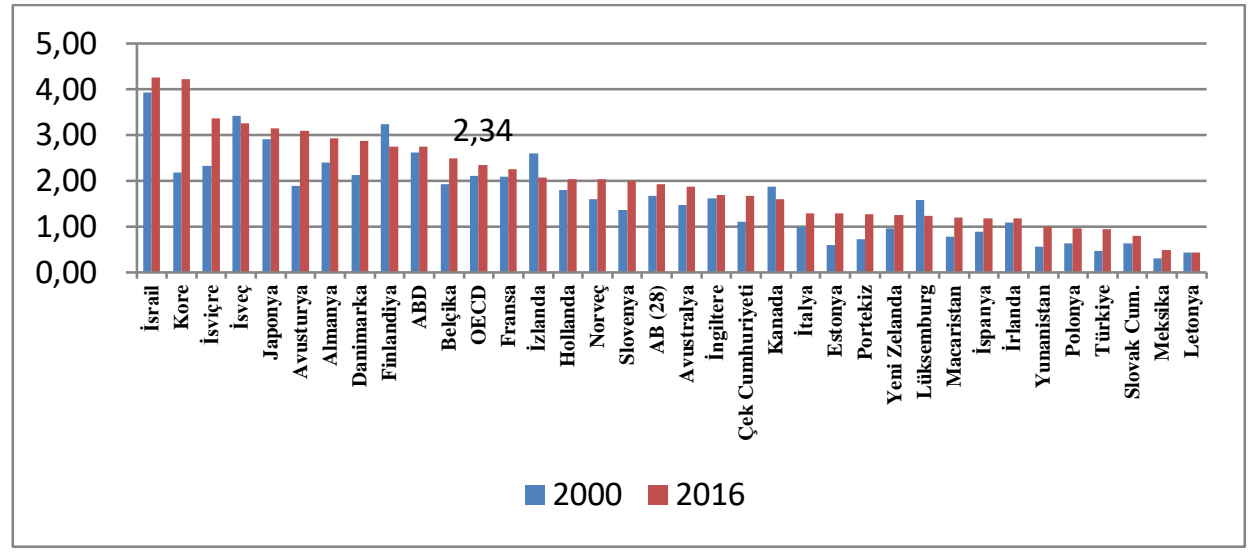

Kaynak: (OECD, 2019)

Grafikteki veriler 2016 yılındaki en yüksek oranlı ülkeden en düşük olana doğru sıralanmıştır. Buna göre OECD ülkeleri içerisinde 2016 yılı verilerine göre en fazla Ar-Ge yoğunluğuna sahip ülke İsrail olup $(4,25)$, onu Kore $(4,23)$, İsviçre $(3,25)$ ve Japonya $(3,14)$ takip etmektedir. En düşük Ar-Ge yoğunluğuna sahip 5 ülke ise Polonya $(0,97)$, Türkiye $(0,94)$, Slovak Cumhuriyeti $(0,79)$, Meksika $(0,49)$ ve Letonya'dır $(0,44)$. Bu 16 yıllık süreç düşünüldügünde İzlanda, 
Finlandiya, Lüksemburg, Kanada ve İsveç'in Ar-Ge yoğunluklarında bir düşüş̧ yaşandığı, en iyi atılımı \%2,18'den \%4,23'e çıkarak Kore'nin gerçekleştirdiği görülmektedir. Avusturya, İsviçre, Danimarka, Estonya ve Slovenya yine en fazla artış gösteren ülkeler konumundadır. Türkiye de bu süreçte Ar-Ge yoğunluğunu yaklaşık 2 kat arttırarak iyi bir performans sergilemiş olsa da, halen OECD ortalamasının $(2,34)$ oldukça gerisinde kalmaktadır.

19. yüzyılın sonlarına doğru başlayıp özellikle İkinci Dünya Savaşı’ndan itibaren hız kazanan bilimsel ve teknolojik çalışmalara, askeri üstünlük ve kamu sağlı̆̆ gibi önemli birçok hedefe hizmet ettiğinden devletler tarafından oldukça önem verilmektedir. Devletin destek verdiği teknolojik çalışmalar neticesinde hem özel sektörün ticari kapasitesi hem de genel toplum refahı artmaktadır. Radar, mikro dalga firın, cep telefonu sistemleri, tıbbi malzemeler, hava taşımacılığı endüstrisi... v.b. ekonomik değerler, devletin finanse ettiği Ar-Ge faaliyetleri sonucunda geliştirilmiştir. Bu öneminden dolayı birçok ülke Ar-Ge çalışmalarını kurumsal hale dönüştürmüş (örneğin; ABD'da kurulan Bureau of Standarts, Almanya'da kurulan Physikalische und Teknische Reichsanstalt, İngiltere'de kurulan National Physical Laboratory) ve bu yolla devletler hem kamu hem de özel sektör araştırmalarını planlama görevini üstlenmiştir (MÜSİAD, 2012: 67,68).

Yayılma etkisi, finansal kısıtlamalar, belirsizlikler, riskten kaçınma ve dinamik dışsallık gibi piyasa başarısızlıkları, firmaların yenilikçi çalışmalar yapma isteğini azaltmaktadır. Bu nedenle birçok iktisatçı özel Ar-Ge faaliyetlerinin devlet tarafindan desteklenmesi ve müdahale edilmesi gerektiğini savunmaktadır (Choiaand Lee, 2017: 1465, Bronzini and Piselli, 2016:443). Devletin Ar-Ge faaliyetlerine dahil olmasındaki en temel ekonomik gerekçe ise müdahil olunmaması halinde belli türden araştırmaları özel sektörün yeterince yapmayacak olmasından kaynaklanmaktadır (Bernanke, 2011:2). Ar-Ge kamu destekleri, genellikle beklenen sosyal faydası büyük, özel yatırımcı açısından beklenen getirileri düşük olan ticari Ar-Ge faaliyetlerini desteklemek amaciyla tasarlanan politika araçlarıdır (Clausen, 2009: 240). Kamu sektörü, Ar-Ge faaliyetlerini desteklerken dokuz hedef gözetmektedir. Bunlardan askeri savunma, kamu sağlığı, hayat kalitesindeki gelişmeler ve uluslararası diplomasiyi içeren dört hedef müstakil; iktisadi korumacılık, yeni iş kolları, yeni işletmeler, ihracat teşvikleri ve yabancı işletme yatımlarını içeren beş hedef ise ekonomik kalkınmanın alt kategorisidir (MÜSİAD, 2012: 70).

Kamu sektörü Ar-Ge politika araçları temelde ikiye ayrılır. Bunlardan birincisi kamu sektörünün bizzat Ar-Ge faaliyetleri yürütmesi, ikincisi ise özel sektörün yürüttüğü yenilik faaliyetlerini desteklemektir. Özel sektör Ar-Ge faaliyetleri ise kamu tarafindan iki temel araç kullanılarak desteklenmektedir: doğrudan destekler (sübvansiyonlar ya da hibe destekleri) ve vergi teşvikleri 
(mali teşvikler, dolaylı teşvikler). Devletin "bizzat" Ar-Ge faaliyetlerini yürütmesindeki amaç temel bilimsel bilginin üretilmesidir. Üniversiteler ve Kamu Araştırma Laboratuarlarında yapılan ve hükümetin finanse ettiği bu çalışmalar neticesinde elde edilen bilgiler, özel sektörün de kullanımına sunulmaktadır. Özel sektörün Ar-Ge faaliyetlerini "doğrudan destek" ile fonlanmasındaki amaç hükümetin politik hedeflerine ulaşmasını sağlamaktır. "Vergi teşvikleri" ile desteklemenin ardında ise Ar-Ge yapan firmalara yardım yapmak amaçlanmaktadır (Erden, 2009: 26,27).

Hem doğrudan destek hem de vergi teşviklerinin her ikisi de firmaların maliyetlerini düşürmek yoluyla Ar-Ge yatırımlarını artırmayı amaçlamaktadır fakat hibeler projeler değerlendirildikten sonra tahsis edilirken vergi teşvikleri otomatik olarak Ar-Ge harcamalarının miktarına göre firmaların vergi yükünü azaltmaktadır. $\mathrm{Bu}$ bağlamda vergi teşvikleri yürütülen projenin türüne bakılmaksızın firmalara fayda sağladığından doğrudan desteklere göre daha tarafsızdır (Bronzini and Piselli, 2016: 443). Diğer taraftan doğrudan desteklere göre vergi teşviklerinin kamuya maliyeti daha azdır ve vergi teşvikleri uzun vadeli Ar-Ge harcamalarını teşvik etmekte daha etkin bir araçtır. Vergi teşvikleri; vergi indirimleri, vergi kredisi, vergi tatili, aşınma indirimleri, Ar-Ge faaliyetleri için kullanılan makine, teçhizat ve bina yatırımlarına hızlandırılmış amortisman sağlamak, Ar-Ge vergi kredisini kurumlar vergisinden mahsup etmek gibi çeşitli bileşenleri içerebilmektedir (Falk, 2004: 4,5). Kullanılan politika araçları ülkeden ülkeye değişmekle beraber, Ar-Ge faaliyetlerindeki sorunlara tam anlamıla bir çözüm sunmasa da vergi teşvikleri, sübvansiyonlara oranla giderek daha çok tercih edilen bir enstrüman haline gelmiştir (Yang et all., 2012: 1579).OECD verilerine göre 2000 yılında doğrudan desteklerin GSMH'ya oranı \% 1,73 iken 2015 yılında \% 2,34 olarak, vergi teşviklerinin GSMH'ya oranının ise aynı yıllar için \% 0,57 ve \% 2,63 olarak gerçekleştiği görülmektedir (OECD, 2019). Bu verilere onbeş yıllık zaman sürecinde doğrudan desteklerde \% 34'lük artış varken vergi teşviklerindeki artış oranı $\% 360$ 'tır.

Teknolojik değişim, ekonomik büyümenin temel belirleyicilerinden biri olarak kabul edildiğinden, yeniliklerin oluşumunu ve yayılmasını teşvik etmek birçok OECD ülkesinin en önemli hedeflerinden birisi olmuştur. Bu nedenle ArGe kamu desteklerine yönelik olarak ekonomistler arasında bir görüş birliği olmasa da son zamanlarda devlet tarafindan firmalara önemli miktarlarda kamu finansmanı imkanı sunulmaktadır (Klette, et all., 2000: 471; Busom, 2000: 111). 
Şekil 2. OECD Ülkelerinin Toplam Ar-Ge Harcamaları ve Toplam Ar-Ge Teşvikleri

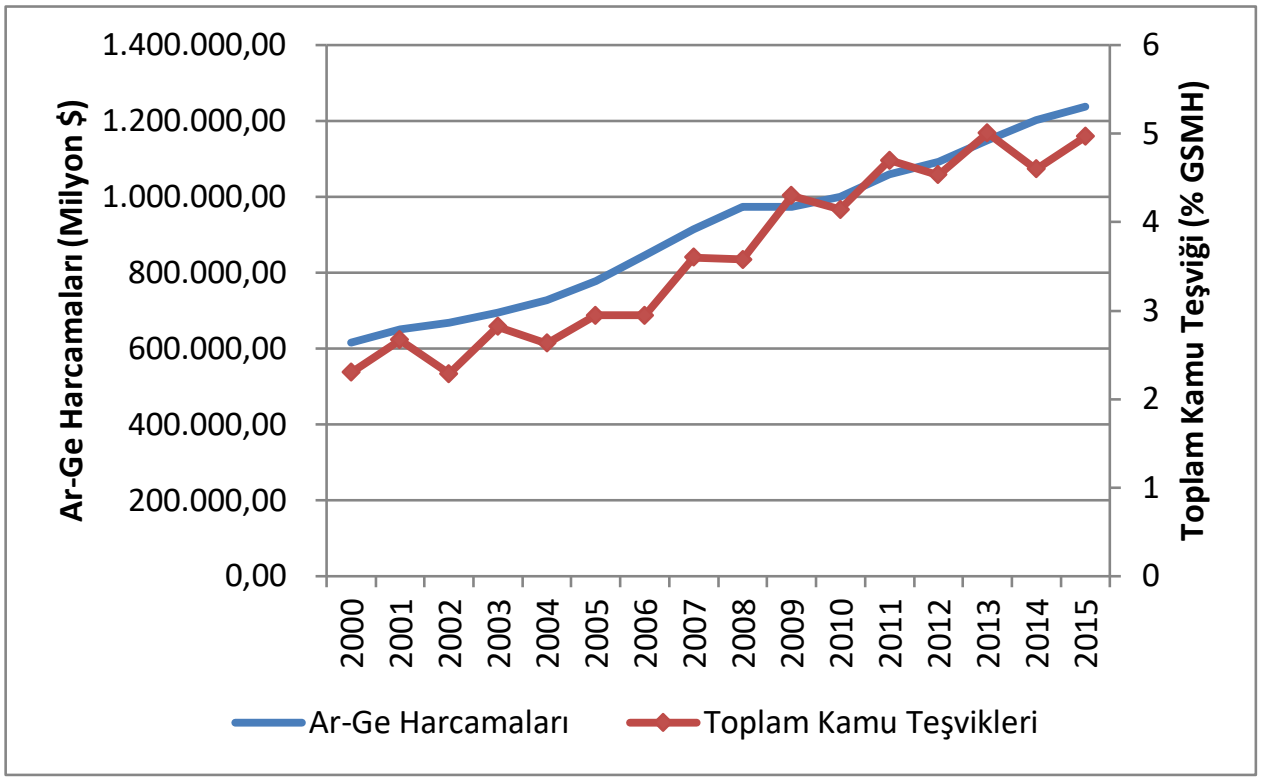

Kaynak: (OECD, 2019).

Şekil 2'de OECD ülkelerinin 2000-2015 yılları arasında yapmış olduğu toplam Ar-Ge harcamaları ile kamu sektörünün özel sektöre doğrudan ve teşvik yoluyla vermiş olduğu toplam teşvik miktarını göstermektedir. Şeklin sol dikey eksenindeki ölçek milyon \$ cinsinden Ar-Ge harcamalarını, sağ dikey eksenindeki ölçek ise toplam kamu teşviklerinin GSMH' ya oranlarını \% cinsinden ifade etmektedir. Şekilden de anlaşılacağ 1 üzere özel sektöre verilen toplam kamu teşviklerinin GSMH'ya oran 2000 yllında \% 2,30 iken 2015 yılında \% 4,96'ya yükselmiştir. 2000 yılında 615.729 milyon \$ olan Ar-Ge harcamaları 2015 yılında ise 1.266 .135 milyon \$'a çıkmıştır. Her iki veri serisinin de yıllar itibari ile artan bir eğilim gösterdiği, yani hem Ar-Ge harcamalarına hem de ArGe için yapılan devlet desteğine daha çok önem verildiği görülmektedir.

\section{INOVASYON VE AR-GE İLIŞKISİ}

Küresel rekabet ortamında inovasyon işletmeler için önemli avantajlar sağlamaktadır. İnovasyon işletmelerin varlığını sürdürebilmesi, pazarda lider konuma gelmesi ve kârlılığını artırması gibi temel problemlerine çözüm getirmeyi amaçlar (Müsiad, 2012: 55). Bunun yanı sıra işletmeler tüketicilerin sürekli değişen ve gelişen ihtiyaçlarını inovasyon yaparak karşılayabilmektedir. İnovasyon faaliyetlerindeki süreklilik işletme kültürünün oluşturulması açısından oldukça önemlidir. Burada önemli olan sadece yeni ve farklı bir şeyler 
oluşturulması değil, ekonomik değer yaratabilen yeniliklerin yapılmasıdır (Şahbaz, 2017: 23).

İnovasyon için sistematik olarak yönetilen Ar-Ge çalışmalarına ihtiyaç duyulmaktadır. $\mathrm{Bu}$ çerçevede Ar-Ge, inovasyonun ön koşulu olarak görülmektedir. Ar-Ge sonucu geliştirilen yenilikçi fikirler, bu yeniliklerin ticarileştirilmesi ile inovasyon olarak ortaya çıkar. Tersi durumda, başka bir deyişle Ar-Ge çıktısı olan uygulanmamış veya ticarileştirilememiş yeni fikirlerin ve projelerin çoğalması, işletmeler ve ülkeler açışından kaynak israfı yaratan bir hal almaktadır.

Ar-Ge faaliyetlerinin inovasyona dönüşmesinde etkili olan bazı temel stratejiler söz konusudur. Bunlardan bazıları kısaca aşağıdaki şekilde özetlenebilir:

Saldırgan İnovasyon Stratejisi: Saldırgan stratejinin temeli teknoloji ve piyasa liderliğini ele geçirmeye dayanır. Bu amaçla yapılan Ar-Ge harcamaları müşteri isteklerine daha hılı cevap vermeyi hedeflerken, yüksek getiri/risk ilişkisini beraberinde getirir.

Savunmaya Yönelik İnovasyon Stratejisi: Savunmacı stratejiler piyasaya öncülük etmek yerine, piyasadaki yeniliklerin takip edildiği stratejilerdir. Bu stratejiyi uygulayan işletmeler, lider olmanın getirdiği risklerden kaçınırken, yüksek getiriden taviz vermek durumundadır.

Taklitçi Strateji: Teknolojik sıçrama ve radikal yenilikler yapmak yerine piyasayı uzaktan hatta geriden takip etmeyi tercih eden işletmelerin kullandığ 1 stratejidir. $\mathrm{Bu}$ stratejiyi izleyen işletmelerin başarılı olması düşük üretim maliyetleriyle çalışabilme yeteneğine bağlıdır.

Bağımlı Strateji: Bağımlı strateji izleyen işletmeler inovasyon faaliyetlerinde güçlü işletmelerin uydusu veya alt kuruluşu olarak çalışırlar. Bu işletmelerde, müşteri talepleri doğrultusunda ürün özelliklerinde değişiklikler yapılır.

Fırsatları İzleme Stratejisi: Rakiplerin inovasyon faaliyetlerini destek noktası olarak kullanan bu stratejiyi izleyen işletmeler, rakiplerin zayıf yönlerinde üstünlük sağlayarak başarı elde etme imkanı ararlar.

Elde Etme Stratejisi: Başka işletmelerde yaratılan bir yeniliğin, çalışanlar tarafından işletmede uygulanması sonucu yeniliğin yapılmasını amaçlayan stratejidir. Böylece diğer işletmelerin yüksek Ar-Ge harcamaları nedeniyle elde ettikleri teknolojik yeniliklerden oldukça düşük maliyetlerle faydalanma imkanı ortaya çıkmaktadır (Müsiad, 2012: 55-56). 


\section{LITERATÜR}

Ar-Ge teşviklerinin inovasyon üretimi üzerindeki etkisini araştıran literatürde yer alan çalışmaların büyük bir kısmı genellikle firma düzeyindeki incelemeleri kapsamaktadır ve bu konuda elde edilen sonuçlar birbirinden farklılık göstermektedir. $\mathrm{Bu}$ çalışmada diğer çalışmalardan farklı olarak teşviklerin inovasyon üzerindeki etkisi makro düzeyde araştırılmıştır.

Konuya yönelik olarak yapılan en önemli çalışmalardan biri Porter ve Stern (2000)'in çalışmalarıdır. 1973-1993 yılları arasında 17 OECD üyesi için yapılan çalışmada inovasyonun belirleyicilerini araştırmak amacıyla panel veri yöntemi kullanılmıştır. Bağımlı değişken olarak inovasyonu temsilen patentler ve kişi başına patent oranları kullanılmıştır. Sonuç olarak, inovasyonun Ar-Ge sektöründeki beşeri sermaye ve ulusal bilgi stoğuyla pozitif olarak ilişkili olduğu, ancak yabancı bilgi kaynakları (ihracat, ithalat) ile negatif ilişkili olduğu ortaya konulmuştur.

Furman vd. (2002) 17 OECD ülkesi için 1973-1995 dönemine ait y1llık verilerle yaptıkları çalışmada bağımlı değişken olarak patentleri kullanmışlardır. Elde edilen sonuçlar, GSYİH, toplam nüfus, Ar-Ge'de istihdam edilen çalışan sayısı ve Ar-Ge harcamalarının inovasyon üzerinde önemli etkileri olduğunu ortaya koymaktadır.

Bilbao-Osorı ve Rodriguez-Pose (2004) çalışmalarında Avrupa ülkelerinde 1995-2000 yılları arasında Ar-Ge faaliyetlerine yapılan yatırımların inovasyon üzerindeki etkilerini incelemişlerdir. Sonuç olarak Ar-Ge faaliyetlerine yapılan yatırımların inovasyon sürecini pozitif etkilediğini ve inovasyonda meydana gelen artışın ise ekonomik büyümeyi artırdığı sonucuna ulaşılmıştır.

Jaumotte ve Pain (2005), 1986-2000 dönemine ilişkin 19 OECD ülkesi için yaptıkları çalışmada, patentler ve Ar-Ge harcamaları arasındaki ilişkiyi özel sektör Ar-Ge harcamaları, kamu sektörü Ar-Ge harcamaları, 25-64 yaş arası nüfus verilerini kullanarak araştırmışlardır. Sonuç olarak, nüfus ve Ar-Ge harcamaları ile patent arasında anlamlı ve pozitif ilişki olduğu, Ar-Ge harcamaları içinde ise özel sektöre ait Ar-Ge harcamalarının inovasyon üzerinde daha etkili olduğu bulgusuna ulaşılmıştır.

Apak, Sarıdoğan ve Uçak (2008), 1990-2004 yılları arasında yüksek gelir düzeyine sahip OECD ülkelerinde inovasyonun makroekonomik belirleyicilerini saptamak amacıyla yaptıkları çalışmada panel veri yöntemini kullanmışlardır. Tahmin sonuçlarına göre, eğitim, Ar-Ge, GSMH ve bilgi ve iletişim teknolojileri yatırımı inovasyon düzeyini pozitif yönde etkilemektedir. 
Sakarya (2009) Türkiye için 1990-2006 dönemini kapsayan çalışmasında inovasyon performansını etkileyen faktörleri araştırmıştır. Sonuç olarak inovasyonu etkileyen temel değişkenlerin patent başvuru sayıları ile kişi başı ArGe harcamaları olduğu bulgusuna ulaşılmıştır.

Czarnitzki vd. (2011), çalışmalarında AR-GE vergi teşviklerinin Kanada'daki imalat sanayi firmalarının inovasyon faaliyetleri üzerindeki etkisini incelemişlerdir. 1999 yılı için yapılan çalışmada parametrik olmayan eşleştirme yaklaşımı kullanılmış ve Ar-Ge vergi teşviklerinin firmaların inovasyon çıktılarını artırdığı sonucuna ulaşıııışıı.

Tüylüoğlu ve Saraç (2012), çalışmalarında 26 gelişmiş ve 18 gelişmekte olan ülke için 1998-2007 yılları arasında inovasyon üretimini belirleyen değişkenleri araştırmışlardır. Dinamik EKK yönteminin kullanıldığ çalışmada ulaşılan sonuçlar gelişmiş ülkelerde inovasyonun genellikle Ar-Ge ve beşeri sermaye yatırımlarına bağlı olduğunu; gelişmekte olan ülkelerde ise inovasyonun gelişmiş ülkelerden yapılan bilgi transferi yoluyla ortaya çıktığını ortaya koymaktadır.

İncekara vd. (2014), 2000-2011 dönemini kapsamayan çalışmalarında Türkiye ve BRICS ülkelerinde Ar-Ge'ye verilen teşviklerin ülke ekonomilerine sağladıkları katkıların Ar-Ge yanlı değiş̧kenler üzerindeki etkilerini Panel veri yöntemini kullanarak araştırmışlardır. Sonuç olarak Ar-Ge harcamalarının uzun dönemde özellikle BRICS ve Türkiye gibi gelişmekte olan ekonomiler için büyümenin ve kalkınmanın belirleyicisi olduğu ifade edilmiştir.

Guo vd. (2016), çalışmalarında devlet tarafından sağlanan Ar-Ge teşviklerinin, patent sayısı, yeni ürünlerden satış ve ihracatla ölçülen firma inovasyon çıktıları üzerindeki etkilerini araştırmışlardır. 1998-2007 yılları arasında Çin'in imalat sanayi firmaları için yapılan çalışmada panel veri yöntemi kullanılmış ve kamu teşviklerinden faydalanan firmaların diğer firmalara oranla daha yüksek teknolojik ve ticarileştirilmiş inovasyon çıktıları ürettiği sonucuna ulaşılmıştır.

Bronzini ve Piselli (2016), 2000'li yılların başlarında Kuzey İtalya bölgesinde uygulanan bir Ar-Ge destek programının, bu programdan faydalanan firmaların inovasyon faaliyetleri üzerindeki etkisini araştırmışlardır. Sonuç olarak söz konusu programın, küçük firmalarda daha belirgin olmak üzere patent başvuruları üzerinde önemli bir etkisi olduğu bulgusuna ulaşılmıştır.

\section{AMPIRIK MODEL}

Çalışmada kullanılan ekonometrik modelin amacı, Ar-Ge teşviklerinin inovasyon sürecindeki etkisini analiz etmektir. Bu amaçla Ar-Ge teşviklerinin inovasyon üzerindeki etkisi yatay kesit analiz yönteminden yararlanılarak OECD 
üyesi ülkeler ${ }^{2}$ için 2016 dönemi baz alınarak test edilecektir. Bu doğrultuda oluşturulan ekonometrik model kapsamında, kişi başına düşen milli gelir, beşeri sermaye, doğrudan yabancı yatırımlar, dışa açıklık ve Ar-Ge teşvikleri açıklayıcı değişken olarak seçilmiştir. İnovasyon ise modelin bağımlı değişkenidir.

İnovasyon sürecinde etkili olan faktörler belirlenirken Furman vd. (2002)'nin çalışmasında kullanılan değişkenler baz alınmıştır. Modelin matematiksel gösterimi şu şekildedir;

$$
\text { IN }=\beta_{0}+\beta_{1} \operatorname{lnKBMG}+\beta_{2} \ln B S+\beta_{3} \mathrm{DYY}+\beta_{4} \mathrm{DA}+\beta_{5} \mathrm{AGT}+\varepsilon_{\mathrm{i}}
$$

Burada İN, inovasyonu gösterirken; açıklayıcı değişkenler lnKBMG, lnBS, DYY, DA ve AGT; sırasıyla doğal logaritması alınmış kişi başına düşen milli gelir ve beşeri sermaye düzeyini, doğrudan yabancı yatırımları, dışa açıklık düzeyini ve AR-GE teşviklerini ifade etmektedir. $\beta_{0}$, sabit terimi, $\beta_{1}, \beta_{5}$ eğim parametrelerini, $\varepsilon_{\mathrm{i}}$ ise hata terimini göstermektedir.

\section{Veriler}

Modelde kullanılan bağımlı ve bağımsız değişkenler ve bu değişkenlere ilişkin verilerin kaynakları aşağıda açıklanmaktadır. Modelde yer alan değişkenlere ait veriler 2016 yılına aittir.

Çalışmada yer alan ekonometrik modelde, bağımlı değişken olan inovasyon için Global Innovation Index değerleri kullanılmıştır. Global Innovation Index, 0 ile 100 arasında değerlerden oluşmaktadır. Buna göre 0 , inovasyon üretiminin en düşük olduğu, 100 ise en yüksek olduğu durumu göstermektedir.

Modelde kullanılan açıklayıcı değişkenlere ilişkin veriler ve kaynağı aşağıda açıklanmaktadır:

Çalışmada açılayıcı değişkenlerden biri olarak kullanılan kişi başına düşen milli gelir rakamlarının satın alma gücü paritesi cinsinden değeri alınmıştır. Çalışmada kullanılan beşeri sermayenin göstergesi olarak tam zaman eşdeğer ArGe personeli sayısı kullanılmıştır. Doğrudan yabancı yatırımlar için, doğrudan yabancı sermaye yatırımlarının gayri safi yurt içi hasılaya oranı kullanılmıştır.

\footnotetext{
${ }^{2}$ Almanya, Avusturya, ABD, Belçika, Kanada, Çek Cumhuriyeti, Şili, Danimarka, Estonya, Finlandiya, Fransa, Japonya, Kıbris, Kore, Hollanda, İngiltere, İrlanda, İspanya, İsveç, İtalya, İsrail, Letonya, Litvanya, Lüksemburg, Macaristan, Malta, Meksika, Polonya, Portekiz, Slovakya, Slovenya, Yunanistan, Yeni Zelanda, Romanya ve Hirvatistan.
} 
Dışa açıklık değişkeni için, mal ve hizmet ithalat ve ihracat toplamının gayri safi yurt içi hasılaya oranı kullanılmıştır. Çalışmada kullanılan diğer açıklayıcı değişken olan AR-GE teşviklerinin göstergesi olarak AR-GE'ye verilen doğrudan ve dolaylı teşviklerin gayri safi yurt içi hasılaya oranı kullanılmıştır. Açıklayıcı değişkenlere ilişkin veriler Dünya Bankası'nın ${ }^{3}$ internet veri sayfasından alınmıştır.

Yukarıda açıklanan değişkenlerin kaynakları ve inovasyon üzerinde olması beklenen etkileri ve Tablo 1'de yer almaktadır.

Tablo 1. Değişkenlerin Kaynağı ve Beklenen İşaretleri

\begin{tabular}{|l|l|c|}
\hline \multicolumn{1}{|c|}{ Değişken } & Değiş̧kenin Kaynağı & Beklenen İşaret \\
\hline Kişi Başına Düşen Milli Gelir & Dünya Bankası & + \\
\hline Beşeri Sermeye & Dünya Bankası & + \\
\hline $\begin{array}{l}\text { Doğrundan Yabancı Sermaye } \\
\text { Yatırımları }\end{array}$ & Dünya Bankası & + \\
\hline Dışa Açıklık & Dünya Bankası & + \\
\hline AR-GE Teşvikleri & Dünya Bankası & + \\
\hline
\end{tabular}

\section{Tahmin Sonuçlarının Değerlendirilmesi}

Çalışmada kullanılan modelde, bağımlı değişken olan inovasyon üretimi ile bağımsız değişkenler olan kişi başına düşen milli gelir, beşeri sermaye, doğrudan yabancı yatırımlar, Ar-Ge teşvikleri ve dışa açıklık değişkenleri arasındaki ilişki incelenmiştir. Söz konusu değişkenler OECD üyesi ülkeler için 2016 yılı verileri kullanılarak yatay kesit analiz yöntemi ile tahmin edilmiştir.

Yatay kesit yönteminin kullanıldığı çalışmalarda en sık karşılaşılan sorun, değişen varyans sorunudur. $\mathrm{Bu}$ nedenle yatay kesit analizlerinde tahminlerin değişen varyans sorununun giderilerek yapılması gerekmektedir. Bu çalışmada değişen varyans sorununun giderilmesi için en çok tercih edilen yöntem olan

\footnotetext{
${ }^{3}$ Internet adresi; databank.worldbank.org
} 
"White heteroskedasticity-consistent standard errors\&covariance" yöntemi (Wooldridge, 2001: 55) kullanılarak model tahmin edilmiştir. Böylece değişen varyans sorunu giderilerek tahminler elde edilmiştir.

Tablo 2. OECD Ülkelerinde Ar-Ge Teşviklerinin İnovasyon Üzerindeki Etkisi

\begin{tabular}{|l|r|r|r|}
\hline \multicolumn{2}{|c|}{ Bağımlı Değişken: GIN } \\
\hline Değişken & Katsayı $^{\mathrm{H}}$ & t istatistiği & p-değeri \\
\hline LNKBMG & 1.988941 & 4.855635 & $0.0001^{*}$ \\
\hline LNBS & 0.255330 & 1.876019 & $0.0753^{* * *}$ \\
\hline DYY & 1.328192 & 3.711861 & $0.0014^{*}$ \\
\hline DA & 0.600628 & 1.241168 & 0.2289 \\
\hline AGT & 0.1412131 & 0.063048 & 0.9504 \\
\hline Sabit Terim & 4,707571 & -1.480633 & $0,0052^{*}$ \\
\hline R ${ }^{2}$ & 0,563853 & & \\
\hline F-statistic & 10,80792 & & \\
\hline $\begin{array}{c}\text { Prob(F- } \\
\text { statistic) }\end{array}$ & 0,00038 & & \\
\hline
\end{tabular}

*: \%1 Anlamlılık düzeyinde istatistiksel olarak anlamlı katsayı

**: \%5 Anlamlılık düzeyinde istatistiksel olarak anlamlı katsayı

***: \%10Anlaml11ık düzeyinde istatistiksel olarak anlamlı katsay1

En küçük kareler (EKK) yöntemi ile elde edilen tahmin sonuçları Tablo 2'de gösterilmiştir. Tahmin edilen ekonomik modele ilişkin $R^{2}$ değeri $0,56^{4}$ olarak

\footnotetext{
${ }^{4}$ Bağımlı değişkendeki değişmelerin ne kadarının bağımsız değişkendeki değişsmeler tarafindan açıklandığını gösteren $\mathrm{R}^{2}$ değeri ekonometrik yöntemler açısından değerlendirildiğinde düşük görülebilir. Bununla birlikte yatay kesit verileri ile yapılan tahminlerden elde edilen $\mathrm{R}^{2}$ 'lerin genel olarak küçük olduğu bilinmektedir. Studenmund (1992: 47) yatay kesit verilerinde 0,50 civarında bir $\mathrm{R}^{2}$ 'nin iyi bir uygunluk olduğunu belirtmiştir (Ağır ve Kar 2010: 167).
} 
saptanmıştır. Buna göre elde edilen $\mathrm{R}^{2}$ değerinin düşük olmaması modelin bir bütün olarak anlamlılığını ortaya koymaktadır. Ayrıca modelde yer alan eğim katsayılarının birlikte anlamlılığını test eden F istatistik sonuçları da modelin anlamlılığını doğrulamaktadır. Bu çerçevede çalışmada kullanılan model gerek $\mathrm{R}^{2}$ gerekse $\mathrm{F}$ istatistik sonuçlarına göre anlamlı olarak test edilmiştir.

Elde edilen ampirik sonuçlara göre, kişi başına düşen milli gelir ile inovasyon üretimi arasında $\% 1$ anlamll1ık düzeyinde istatistiksel olarak anlamlı ve pozitif bir ilişki bulunmaktadır. Başka bir deyişle kişi başına düşen milli gelirdeki 1 birimlik artış inovasyon üretimi üzerinde 1.988941 puanlık bir artışa yol açmaktadır.

Diğer bir açıklayıcı değişken olan beşeri sermaye değişkeninin inovasyan üretimi üzerinde $\% 10$ anlamlllık düzeyinde istatistiksel olarak anlamlı ve pozitif yönlü bir etkiye sahip olduğu sonucuna ulaşılmıştır. Bu durumda beşeri sermaye düzeyindeki 1 birimlik bir artış inovasyon üzerinde 0.255330puanlık bir artışa neden olmaktadır.

Modelin tahmin sonuçlarına göre, doğrudan yabancı yatırımlar ile inovasyon arasında $\% 1$ anlamlılık düzeyinde istatistiksel olarak anlamlı ve pozitif yönlü bir iliş̧ki bulunmaktadır. Doğrudan yabancı yatırımlardaki 1 birimlik bir artış inovasyon üzerinde 1.328192puanlık bir artışa neden olmaktadır.

Diğer bir açıklayıcı değişken olan dışa açıklık oranının inovasyon üzerinde gerek $\% 5$ gerekse $\% 10$ anlamlılık düzeyinde istatistiksel olarak anlamlı bir etkiye sahip olmadığı sonucuna ulaşılmıştır.

Elde edilen ampirik sonuçlara göre AR-GE teşviklerinin inovasyon üzerinde gerek $\% 5$ gerekse $\% 10$ anlamlılık düzeyinde istatistiksel olarak anlamlı bir etkiye sahip olmadığı sonucuna ulaşılmıştır.

\section{SONUÇ}

İnovasyon günümüzde gerek firmalar gerekse ülkeler açısından rekabetin ve büyümenin en önemli araçlarından biri olarak görülmektedir. $\mathrm{Bu}$ durum inovasyona dayalı büyümeyi hedefleyen ekonomi politikalarına olan ilgiyi artırmışıı. Bu nedenle, politika yapıcılar Ar-Ge ve patent gibi inovasyon faaliyetlerine büyük önem vermektedirler (Demirel ve Mazzucato, 2012). İnovasyon ekonomisi üzerine yapılan çalışmalar, inovasyon ile ekonomik büyüme arasında nedensel bir ilişki olduğunu göstermektedir.

İnovasyon sürecinde kaynakların en uygun şekilde tahsis edilmesini sağlamak için, birçok gelişmiş sanayi ülkesinde sübvansiyonlar veya mali teşvikler yoluyla Ar-Ge faaliyetlerini destekleyen politikalar söz konusudur. Bu politikalar, 
inovasyon yatırımlarını teşvik etmek için yenilikçi harcamaların maliyetlerini azaltmayı amaçlamaktadır (Bronzini ve Piselli, 2016)

İnovasyon üzerinde, $\mathrm{Ar}-\mathrm{Ge}$ teşviklerinin etkisini araştıran ampirik çalışmalarda oldukça farklı sonuçlar söz konusudur. Örneğin Griliches ve Regev (1998), Branstetter ve Sakakibara (1998) devlet desteklerinden faydalanan firmaların İsrail ve Japonya'da daha yüksek verimlilik ve karlılık elde ettiklerini tespit etmişlerdir. Bununla birlikte, önemli sayıda çalışmada ise kamu Ar-Ge teşviklerinin firma performansını artırmadığı veya küçük firmalar dışında, firmaların Ar-Ge harcamaları üzerindeki olumlu etkilerinin sınırlı kaldığı gösterilmiştir (Klette ve Moen, 1999; Brander vd., 2008).

Hazırlanan bu çalışmada, inovasyon ile Ar-Ge teşvikleri arasındaki ilişki yatay kesit analiz yöntemi ile tahmin edilmiştir. Bu doğrultuda OECD üyesi ülkelerin 2016 yılına ait verileri kullanılarak ekonometrik bir çalışma hazırlanmıştır $\mathrm{Bu}$ çerçevede; inovasyon ve diğer açıklayıcı değişkenlerden oluşan bir model oluşturulmuş (kişi başına düş̧en milli gelir, beşeri sermaye, doğrudan yabancı yatırımlar, dışa açıklık ve Ar-Ge teşvikleri) ve aralarındaki ilişki test edilmiştir.

Çalışmadan elde edilen sonuçlar, inovasyon ile Ar-Ge teşvikleri arasında istatistiksel olarak anlamlı bir ilişki olmadığını ortaya koymaktadır. Bununla birlikte modelde kullanılan dışa açıklık değişkeni dışındaki diğer değişkenler ile inovasyon üretimi arasında istatistiksel olarak anlamlı ve beklenen yönde bir etkileşim olduğu sonucuna ulaşı1mıştır. Buna göre, kişi başına düşen milli gelir,beşeri sermaye ve doğrudan yabancı yatırımlarda meydana gelen bir artış, inovasyon üretimini artırmaktadır.

Sonuç olarak, Ar-Ge desteklerinin başarısı için, uygulanan politika araçlarının stabil olması ve inovasyon faaliyetlerinin uzun dönemli yatırımlar olarak düşünülmesi gerekmektedir. Bu çalışmada OECD ülkelerinde teşvikler ile inovasyon arasında bir ilişki bulunamamış olsa da farklı ülke grupları ve zaman dilimleri için farklı sonuçlar elde edilebilir.

\section{KAYNAKÇA}

Ağır, Hüseyin ve Kar, Muhsin (2010), “Türkiye'de Elektrik Tüketimi ve Ekonomik Gelişmişlik Düzeyi İlişkisi: Yatay Kesit Analizi”, Sosyoekonomi, Özel Sayı.

Akçomak, İsmail Semih ve Kalaycı, Elif (2016), “Ar-Ge ve Yeniliğin Ölçümü ve Ar-Ge ve Yenilik Anketi Verilerinin Araştırmada Kullanılması”, TEKPOL Working Paper Series, STPS-WP-16/03, http://stps.metu.edu.tr/sites/stps.metu. edu.tr /files/WP\%2016\%3A03.pdf (20.02.2019). 
Apak, Sudi; Sarıdoğan, Ercan ve Uçak, Ayhan (2008), "Macroeconomic Determinants of Innovation”, International Conference Patent and Innovation, Tokyo, Japan, December 19-20, Applied Econometric Association.

Bilbao-Osorio, Benat and Rodriguez-Pose, Andres (2004), "From R\&D to Innovation and Economic Growth in the EU”, Growth and Change, Vol. 35 No. 4, pp. 434-455.

Bernanke, Ben Shalom (2011), "Promoting Research and Development: The Government's Role”, New Building Blocks for Jobs and Economic Growth Conferance, Georgtown University, May 16.

Brander, James A.; Egan, Edward and Hellmann, Thomas F. (2008), "Government sponsored versus private venture capital: Canadian evidence” NBER Working Paper (No. w14029).

Branstetter, Lee and Sakakibara, Mariko (1998), “Japanese research consortia: A microeconometric analysis of industrial policy”, J. Ind. Econ. 46 (2), pp. 207-233.

Bronzini, Raffaello and Piselli, Paolo (2016), “The impact of R\&D subsidies on firm innovation”, Research Policy, 45, pp. 442-457.

Busom, Isabel (2000), “An Empirical Evaluation of The Effects of R\&D Subsidies”, Economics of Innovation and New Technology, 9:2, pp. 111148.

Choia, Joonhwan, and Lee, Jaegul (2017), "Repairing the R\&D market failure: Public $R \& D$ subsidy and the composition of private $R \& D$ ", Researh Policy, 46, pp.1465-1478.

Clausen, Tommy H. (2009), “Do subsidies have positive impacts on R\&D and innovation activities at the firm level?”, Structural Change and Economic Dynamics, 20, pp. 239-253.

Czarnitzki, Dirk; Hanel, Petr and Rosa, Julio Miguel (2011), "Evaluating the Impact of R\&D Tax Credits on Innovation: a Microeconometric Study on Canadian Firms”, Research Policy, 40, pp. 217-229

Dünya Bankas1, https://databank.worldbank.org (15.02.2019)

Erden,Yelda (2009), “Kamu Ar-Ge Destekleri ve Yenilik Modelleri: Kamu Ar-Ge Politikalarının Meşrulaştırılması İçin Hangi Yenilik Modeli Seçilmeli?”, Ekonomi Bilimleri Dergisi, 1 (2), ss. 25-39. 
Falk, Martin (2004), “What Drives Business R\&D Intensity Across OECD Countries?”, Austrian Institute of Economic Research WIFO, No. 236.

Furman, L. Jeffrey; Porter, E. Michael and Stern, Scott (2002), "The Determinants of National Innovative Capacity”, Research Policy, 31, pp. 899-933.

Griliches, Zvi and Regev, Haim (1998). “An econometric evaluation of hightech policy in Israel”, Paper presented at ATP-conference in Washington, DC.

Guo, Di; Guo, Yan and Jiang, Kun (2016), “Government-subsidized R\&D and firm innovation: Evidence from China”, Research Policy, No:45, 11291144.

İncekara, Ahmet; Demez, Selim ve Akyol, Mehmet (2014), “Ar-Ge Harcamalarına Yapılan Teşviklerin Etkinliği: Türkiye BRICS Ülkeleri Karşılaştırmalı Analiz", Journal of Economıc Policy Researches, Cilt:1, Sayı: 2, ss. 1-30.

Jaumotte, Florence and Pain, Nigel (2005), “An Overview of Public Policies to Support Innovation”, OECD Economics Department Working Papers, No: 456, OECD Publishing.

Klette, Tor Jakob and Moen, Jarle (1998), “From growth theory to technology policy: coordination problems in theory and practice”, Nord. J. Polit. Econ. 25, pp. 53-74.

MÜSİAD (2012), Küresel Rekabet İçin Ar-Ge ve İnovasyon, Müsiad Araştırma Raporları:76, İstanbul.

OECD, (2019), Main Science and Technology Indicators, https://stats.oecd.org/Index.aspx?DataSetCode=MSTI_PUB, 13.02.2019.

Porter, Michael E. and Stern, Scott (2000), “Measuring the 'Ideas' Production Function: Evidence from International Patent Output”, NBER Working Paper, No: 7891.

Sakarya, Arif Orçun (2009), "Variables Affecting Innovation-Related Competitiveness in Turkey", Innovation Policies, Business Creation and Economic Development, (Ed.: Neslihan Aydoğan), Springer Science and Business Media: New York, pp. 63-84.

Studenmund, A.H. (1992). Using Eonometrics: A Practical Guide. Second Edition, New York: Harper Collins Publishers. 
Tüylüoğlu, Şevket ve Saraç, Şenay (2012), “Gelişmiş ve Geliş̧mekte Olan Ülkelerde İnovasyonun Belirleyicileri: Ampirik bir Analiz”, Eskişehir Osmangazi Üniversitesi, İ.İ.B.F., Dergisi, 7(1), ss. 39-74.

Wooldridge, Jeffrey M. (2001), Econometric Analysis of Cross Section and Panal Data. The MIT Press, Cambridge, London.

Yang, Chih Hai; Huang, Chia Hui and Hou, Tony Chieh Tse (2012), “Tax incentives and R\&D activity: Firm-level evidence from Taiwan”, Research Policy, 41, pp. 1578-1588. 